Research Article

\title{
Synthesis and In Vitro Antimicrobial and Anthelminthic Evaluation of Naphtholic and Phenolic Azo Dyes
}

\author{
Joseph Kwasi Adu (D), Cedric Dzidzor Kodjo Amengor ${ }^{1}{ }^{2}$ \\ Nurudeen Mohammed Ibrahim (D, ${ }^{1}$ Cynthia Amaning-Danquah, ${ }^{3}$ Charles Owusu Ansah, ${ }^{1}$ \\ Dorcas Dzifa Gbadago, ${ }^{1}$ and Joseph Sarpong-Agyapong ${ }^{1}$
}

\author{
${ }^{1}$ Department of Pharmaceutical Chemistry, Faculty of Pharmacy and Pharmaceutical Sciences, College of Health Sciences, \\ Kwame Nkrumah University of Science and Technology (KNUST), Kumasi, Ghana \\ ${ }^{2}$ Department of Pharmaceutical Chemistry, School of Pharmacy, University of Health and Allied Sciences, Ho, Ghana \\ ${ }^{3}$ Department of Pharmacology, Faculty of Pharmacy and Pharmaceutical Sciences, College of Health Sciences, \\ Kwame Nkrumah University of Science and Technology (KNUST), Kumasi, Ghana
}

Correspondence should be addressed to Joseph Kwasi Adu; jkadu2000@yahoo.com

Received 29 February 2020; Accepted 11 May 2020; Published 1 June 2020

Academic Editor: Sukla Biswas

Copyright (c) 2020 Joseph Kwasi Adu et al. This is an open access article distributed under the Creative Commons Attribution License, which permits unrestricted use, distribution, and reproduction in any medium, provided the original work is properly cited.

\begin{abstract}
The antimicrobial activity of 2-naphtholic and phenolic azo compounds was determined against seven microbial species, Staphylococcus aureus (ATCC 25923), Streptococcus pyrogenes (clinical), and Enterococcus faecalis (ATCC 29212), Salmonella typhi (clinical), Pseudomonas aeruginosa (ATCC 27853), Escherichia coli (ATCC 251922), and Candida albicans (ATCC 10231), using the high-throughput spot culture growth inhibition assay (HT-SPOTi). The minimum inhibitory concentrations (MIC) were determined for the active azo dyes. All the azo compounds (A1-B4) were screened for anthelmintic activity against adult Ghanaian earthworms, Hyperiodrilus spp. As part of the systematic investigation for biological activity, all the azo compounds exhibited good antimicrobial activity against the seven human pathogenic microorganisms. All the compounds exhibited anthelminthic activity against adult Ghanaian earthworms, Hyperiodrilus spp.
\end{abstract}

\section{Introduction}

Over the past decades, the emergence of resistant pathogens in humans has been on the ascendency and has become a global health concern in chemotherapy of infectious diseases [1]. This has therefore stimulated efforts in the field of antimicrobial chemotherapy search for novel drugs to curtail this menace [2]. Bacterial resistance is an inevitable consequence of evolution, and without continued replacement of current antibacterial agents, humanity runs the risk of returning to a preantibiotic era [3]. A section of neglected tropical diseases are associated with helminths, and they are amongst the most common ones affecting the world and posing major public health threat, thus contributing to high morbidity and mortality $[3,4]$. The existence of few antimicrobials and anthelminthics coupled with current chemotherapy losing their efficacy calls for continuous research for new but more effective compounds in the drug discovery industry $[5,6]$.

With regards to this assertion, azo compounds have been found to be useful, extending the scope of drug design and allowing different mechanisms of action [7,8]. The increasing interest in the development of azo compounds is due to their functions and versatile biological activities including antimicrobial, anti-inflammatory, anthelminthic, antiviral, and anticancer effects $[9,10]$. Typical examples of azo dye compounds which are drugs include phenazopyridine, which is a urinary tract analgesic, and sulfasalazine for inflammatory bowel disease (Figure 1).

Although they are synthetically feasible by simple standard diazotisation and coupling reactions, there is still more to be carried out particularly with regards to 


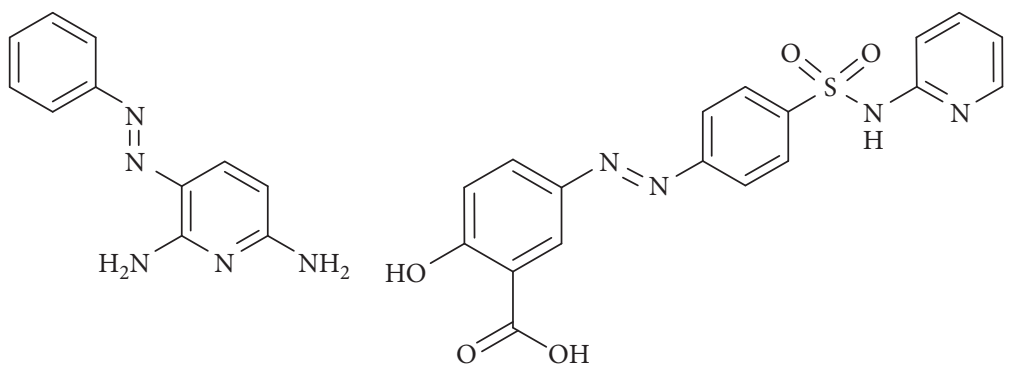

(a)

(b)

FigURE 1: Chemical structures of current azo-based drugs: (a) phenazopyridine and (b) sulfasalazine.

diversification of functional groups [11]. Following on this trajectory, we present herein our findings on the synthesis and in vitro antimicrobial and anthelminthic evaluation of naphtholic and phenolic azo dyes derived from the coupling of various primary aromatic amines with 2-naphthol and phenol. Scheme 1 represents a general synthetic pathway for the azo dyes with their proposed names. The eight azo compounds are [A1] (E)-4-((2-hydroxynaphthalen-1-yl) diazenyl) benzoic acid, [A2] (E)-1-((4-chlorophenyl) diazenyl) naphthalen-2-ol, [A3] (E)-ethyl 4-((2-hydroxynaphthalen-1-yl) diazenyl) benzoate, [A4] (E)-4-((2hydroxynaphthalen-1-yl) diazenyl) benzene sulphonamide, [B1] (E)-4-((4-hydroxyphenyl) diazenyl) benzoic acid, [B2] (E)-ethyl 4-((4-hydroxyphenyl) diazenyl) benzoate, [B3] (E)-4-((2-chloro-4-nitrophenyl) diazenyl) phenol, and [B4] (E)-4-(4-nitrophenyl) diazenyl) phenol. These compounds are coded based on their reacting components and are shown in Table 1 . The synthesised azo compounds were then investigated for their antimicrobial and anthelminthic activities.

\section{Materials and Methods}

2.1. Chemistry and Instrumentation. All reagents and solvents used in this present study were obtained from $\mathrm{BDH}$ chemicals as analytical or technical grade. Reaction progress was monitored using thin layer chromatography, which was performed by employing precoated silica gel plate (Merck $\mathrm{F}_{254}$ ) and visualised with UV light (254 nm and $357 \mathrm{~nm}$ ) or iodine vapour where necessary. Melting point data of the synthesised compounds were obtained by using one end or open capillary tubes on a Gallenkamp melting point apparatus (England) and are uncorrected. Compounds were purified by recrystallisation from suitable solvents appended to synthetic data in Table 1. Infrared (IR) spectra were recorded using FTIR PerkinElmer in the range $400-4000 \mathrm{~cm}^{-1}$. Ultraviolet-visible (UV-vis) spectra were measured on a PerkinElmer spectrophotometer at $200-800 \mathrm{~nm}$ in methanol.

2.2. Synthesis of the Azo Compounds. The synthesis of naphtholic and phenolic azo compounds is presented in Schemes 1 and 2 .

Into a round-bottom flask $(50 \mathrm{~mL})$ equipped with a magnetic stirring bar, a mixture of primary aromatic amine
(10 mmol) and concentrated $\mathrm{HCl}(36 \% \mathrm{w} / \mathrm{v})$ was stirred until a clear solution was obtained. This solution was cooled to $0^{\circ} \mathrm{C}-5^{\circ} \mathrm{C}$, and a solution of sodium nitrite in water $(10 \mathrm{ml})$ was then added dropwise maintaining the temperature below $5^{\circ} \mathrm{C}$. The diazonium salt solution was covered and kept in the ice bath. Starch iodide paper was used to test for the formation of diazonium salt-spontaneous formation of blueblack coloration. The diazonium salt was used immediately for the coupling reaction.

2.2.1. Step II: Coupling Procedure. Into a round-bottom flask $(50 \mathrm{~mL})$, the corresponding 2-naphthol or phenol $(10 \mathrm{mmol})$ was dissolved in $\mathrm{NaOH}(10 \% \mathrm{w} / \mathrm{v}, 50 \mathrm{ml})$ and cooled to $0^{\circ} \mathrm{C}-5^{\circ} \mathrm{C}$ in an ice bath. This solution was then gradually added to the cooled diazonium salt solution, and the resulting mixture was stirred at $0^{\circ} \mathrm{C}-5^{\circ} \mathrm{C}$ for $1 \mathrm{~h}$. The resulting crude precipitate was filtered, washed several times with cold water, and recrystallized from appropriate solvent to yield the final azo compound [12] (Table 1).

\subsection{Antimicrobial Activity}

2.3.1. Culture Media and Reference Antibiotics. Nutrient agar and broth as well as Saboraud dextrose agar and broth were purchased from Oxoid Limited, Basingstoke, United Kingdom. Ciprofloxacin, cefuroxime, amoxycillin, and clotrimazole were obtained from Sigma Aldrich ${ }^{\mathrm{TM}}$ (Michigan, USA).

2.4. Source of Test Organisms. Gram-positive bacteria, Gram-negative bacteria, and fungi were used, including five type strains of bacteria and five clinical strains. Gramnegative bacteria included Escherichia coli (ATCC 25922), Pseudomonas aeruginosa (ATCC 27853), and Salmonella typhi. Gram-positive bacteria included Staphylococcus aureus (ATCC 25923) and Streptococcus pneumoniae (ATCC 49691). Clinical fungal strain included Candida albicans (ATCC 10231). The test organisms were all obtained from the Department of Biological Sciences, Kwame Nkrumah University of Science and Technology (KNUST), Kumasi, Ghana. They were maintained on nutrient agar slants containing $30 \%$ glycerol and stored at $-4^{\circ} \mathrm{C}$ in a frost-free freezer in the Microbiology laboratory section at the 


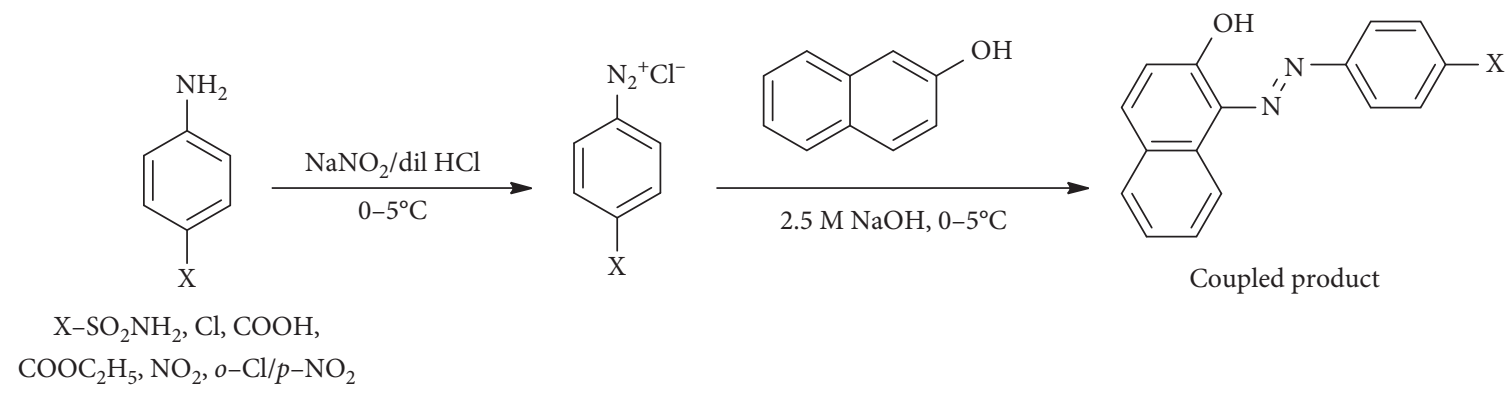

Scheme 1: General reaction for the synthesis of the naphtholic azo compounds [12].

Department of Pharmaceutics, Kwame Nkrumah University of Science and Technology (KNUST), Kumasi, Ghana.

\subsubsection{Step I: Preparation of the Standard 96-Well Plates.} An amount of agar medium was melted in a steam bath or in a microwave oven. It was placed in a water bath and kept at a temperature of $55^{\circ} \mathrm{C}-60^{\circ} \mathrm{C}$ to prevent it from solidifying. A stock concentration of $50 \mathrm{mg} / \mathrm{ml}$ was prepared initially using methanol in a polymerase chain reaction (PCR) half-skirted 96-well plate to give a wide concentration range. Eleven different concentrations of azo compounds and reference drugs (ciprofloxacin, cefuroxime, amoxicillin, and fluconazole) were prepared using serial dilution. Each compound $(2 \mu \mathrm{L})$ and reference drug dilution was pipetted and transferred into their corresponding wells in a standard 96-well plate, and the melted agar $(200 \mu \mathrm{L})$ was dispensed. The wellplates were then shaken for $10 \mathrm{~s}$ to mix thoroughly. After the agar medium was dispensed, the plates were left in a safety cabinet undisturbed to solidify [13].

2.4.2. Step II: Spotting and Incubation of Prepared Well Plates. Bacterial suspension $\left(2 \mu \mathrm{L} ; 1 \times 10^{6} \mathrm{cfu} / \mathrm{ml}\right)$ was pipetted with a micropipette on to each well of the 96-well plate (each microorganism per plate) and allowed it to be absorbed into the agar for $5 \mathrm{~min}$. The plates were sealed with parafilm and wrapped with aluminium foil. The plates were incubated inverted at $37^{\circ} \mathrm{C}$. The growth was observed after $24 \mathrm{hrs}$. The well containing the lowest concentration of a compound for which no growth is observed and recorded within the incubation period is determined as the MIC (minimum inhibitory concentration) of that compound against the organisms [13].

\subsubsection{Step III: Minimum Inhibitory Concentration (MIC)} Determination. Different concentrations of the azo compounds were tested against a panel of Gram-positive bacteria (Staphylococcus aureus, Enterococcus faecalis, and Streptococcus pyogenes), Gram-negative bacteria (Salmonella typhi, Escherichia coli, and Pseudomonas aeruginosa), and a fungus (Candida albicans) to determine their minimum inhibition concentrations (MICs) using the high-throughput spotculture growth inhibition assay (HT-SPOTi).

In the HT-SPOTi assay, molten agar maintained at $55^{\circ} \mathrm{C}-60^{\circ} \mathrm{C}$ was dispensed into 96 -well plates to which $2 \mu \mathrm{L}$ of serially diluted azo compounds have been added starting from a stock of $50 \mathrm{mg} / \mathrm{mL}$. Bacterial suspension $(2 \mu \mathrm{L}$; $1 \times 10^{6} \mathrm{cfu} / \mathrm{ml}$ ) was added to each plate sealed and incubated for 18-24h. The lowest concentration at which bacterial growth was completely inhibited by the compound was observed visually, and the MIC was recorded. The reference drugs used were ciprofloxacin, cefuroxime, amoxicillin, and fluconazole [13].

\subsection{Anthelminthic Activity}

2.5.1. Reagents and Reference Antibiotics. The reagents used included methanol (BDH Chemicals), dimethyl sulphoxide (DMSO) (BDH Chemicals) (ACS grade $\geq 99 \%$ ), and piperazine citrate (Sigma Aldrich).

The procedure for screening for the anthelminthic activity was with reference to Raghavendra and Kumar [14]. The anthelminthic activity was carried out on adult Ghanaian worms, Hyperiodrilus spp. The worms were collected from a local moist habitat and prior assay. They were washed with water to remove dirt, soil, and faecal matter from the skin of the worm. They were divided into groups in three Petri dishes with each containing three adult worms. Dimethyl sulphoxide (DMSO, 0.5\% v/v) was used as the control, while piperazine citrate was used as a reference standard for this assay. Concentrations of $0.625,1.25,2.5$, and $5 \mathrm{mg} / \mathrm{ml}$ were prepared for each of the azo compounds and the standard drug solutions. Three adult worms (triplicate determination) were then introduced into the Petri dishes containing solutions of the azo compounds and the standard drug. The worms in the Petri dishes were observed, and time taken for paralysis and death of worms were recorded. Paralysis was said to occur when the worms do not recover in DMSO $(0.5 \% \mathrm{v} / \mathrm{v})$. The worms were declared dead if there was no movement when shaken vigorously in warm water $\left(50^{\circ} \mathrm{C}\right)$ associated with change in body color (fading to pale). The results are expressed as mean \pm SEM (standard error of mean). Statistical differences were carried out using the analysis of variance and were considered significant when $p<0.05$ (Table 2).

\section{Results and Discussion}

Table 1 shows the physicochemical properties including calculated molecular weights, percentage yields, melting 


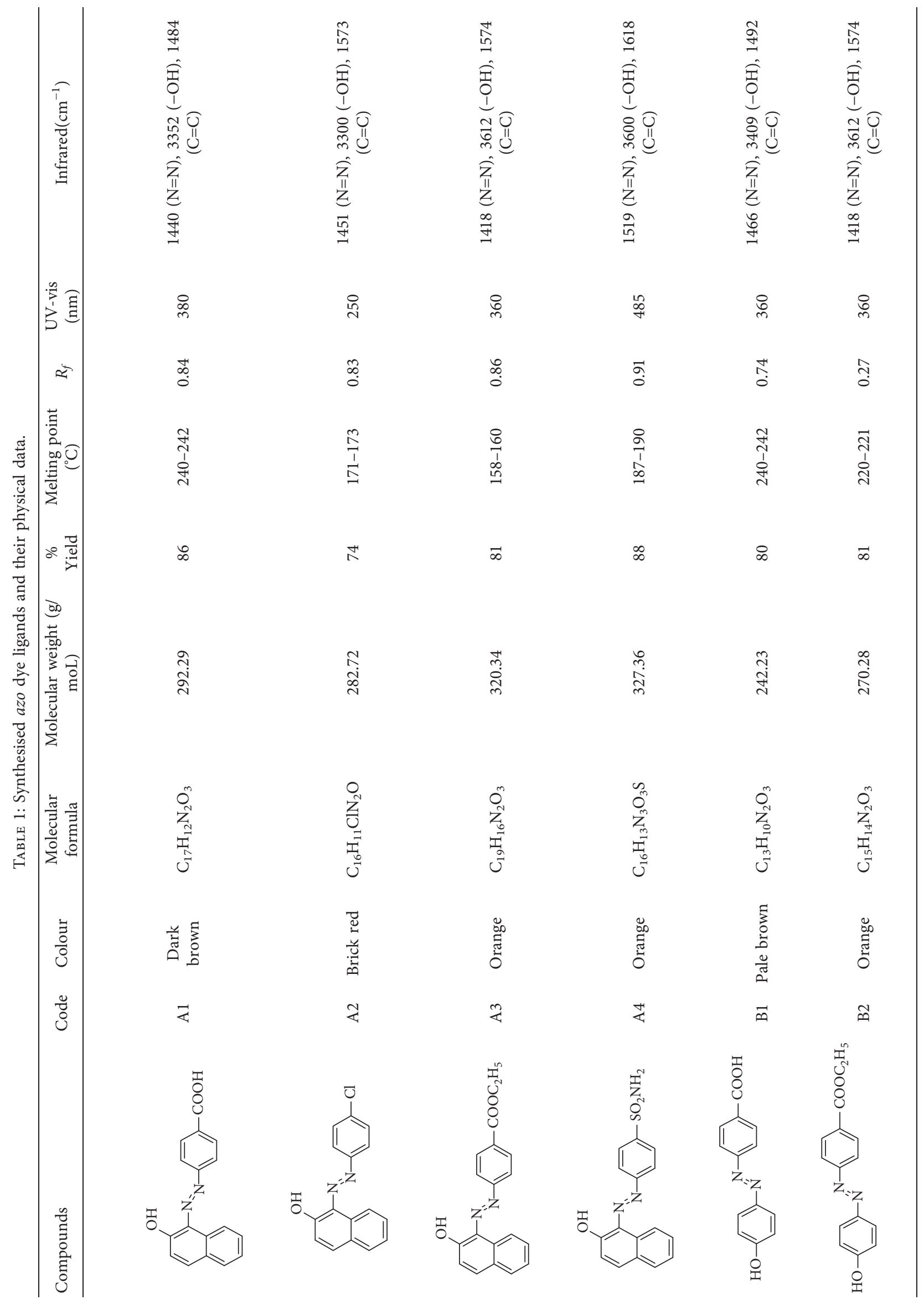




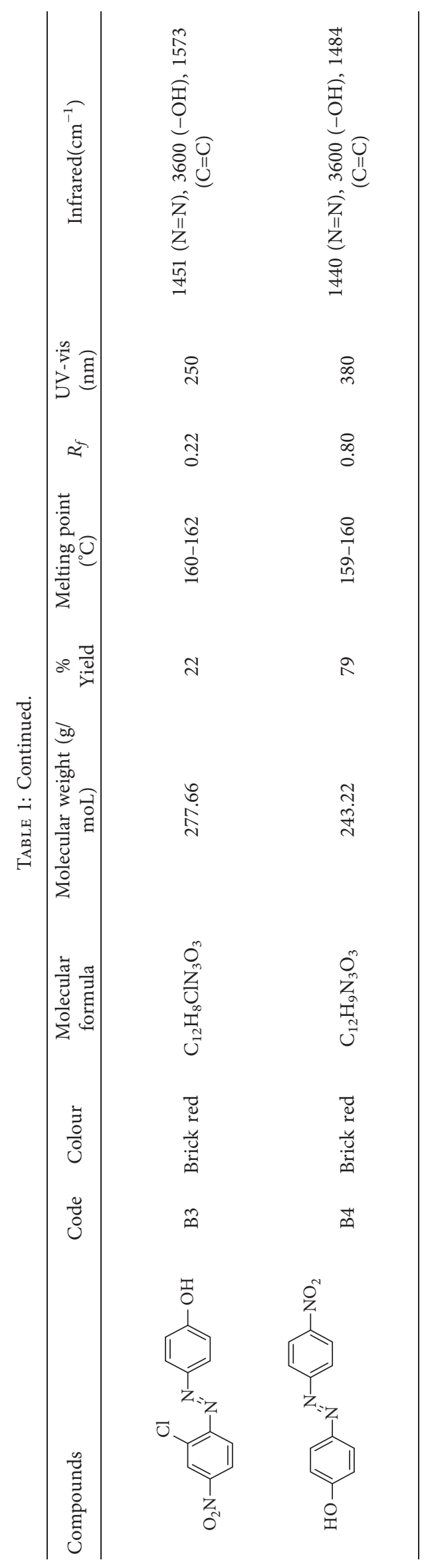




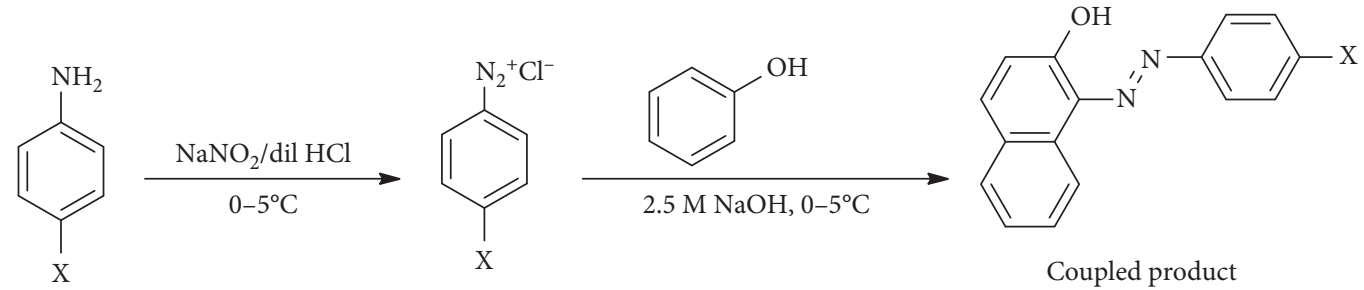

$\mathrm{X}-\mathrm{COOH}, \mathrm{COOC}_{2} \mathrm{H}_{5}, o-\mathrm{Cl} / p-\mathrm{NO}_{2}$

Scheme 2: General reaction for the synthesis of the phenolic azo compounds [12].

TABle 2: Anthelminthic activity.

\begin{tabular}{lcccccc}
\hline Compounds & \multicolumn{2}{c}{$5 \mathrm{mg} / \mathrm{mL}$} & \multicolumn{2}{c}{$2.5 \mathrm{mg} / \mathrm{mL}$} & \multicolumn{2}{c}{$1.25 \mathrm{mg} / \mathrm{mL}$} \\
& $\begin{array}{c}\text { Paralysis time } \\
(\mathrm{min})\end{array}$ & $\begin{array}{c}\text { Death time } \\
(\mathrm{min})\end{array}$ & $\begin{array}{c}\text { Paralysis time } \\
(\mathrm{min})\end{array}$ & $\begin{array}{c}\text { Death time } \\
(\mathrm{min})\end{array}$ & $\begin{array}{c}\text { Paralysis time } \\
(\mathrm{min})\end{array}$ & $\begin{array}{c}\text { Death time } \\
(\mathrm{min})\end{array}$ \\
\hline $\begin{array}{l}\text { Negative control } \\
\text { (DMSO) }\end{array}$ & - & - & - & - & - & - \\
Piperazine citrate & 9 & 10 & 11 & 13 & 24 & $13 \pm 2.64$ \\
A1 & $44 \pm 2.84$ & $52 \pm 2.02$ & $74 \pm 1.73$ & $106 \pm 2.08$ & $114 \pm 1.52$ \\
A2 & $74 \pm 0.88$ & $116 \pm 0.88$ & $206 \pm 3.7$ & $259 \pm 1.73$ & $250 \pm 1.45$ & $320 \pm 2.08$ \\
A3 & $23 \pm 2.90$ & $25 \pm 2.64$ & $35 \pm 3.00$ & $49 \pm 2.02$ & $47 \pm 1.45$ & $55 \pm 0.60$ \\
A4 & $26 \pm 0.66$ & $27 \pm 0.41$ & $46 \pm 1.45$ & $49 \pm 1.46$ & $61 \pm 0.57$ & $62 \pm 2.02$ \\
B1 & $18 \pm 0.44$ & $69 \pm 2.02$ & $32 \pm 1.96$ & $98 \pm 2.08$ & $34 \pm 0.33$ & $108 \pm 0.88$ \\
B2 & $24 \pm 0.59$ & $73 \pm 1.45$ & $29 \pm 1.17$ & $99 \pm 1.76$ & $50 \pm 2.52$ & $118 \pm 2.3$ \\
B3 & $30 \pm 0.88$ & $39 \pm 1.76$ & $35 \pm 0.57$ & $42 \pm 2.08$ & $37 \pm 0.88$ & $45 \pm 2.08$ \\
B4 & $32 \pm 0.88$ & $35 \pm 0.08$ & $33 \pm 0.88$ & $37 \pm 1.17$ & $36 \pm 0.57$ & $39 \pm 0.41$ \\
\hline
\end{tabular}

Results are given in mean \pm SEM and analyzed by ANOVA * $p$ value $<0.05$ compared to standard drug.

TABLE 3: Antimicrobial activity of the synthesised azo compounds.

\begin{tabular}{|c|c|c|c|c|c|c|c|}
\hline Compounds & $\begin{array}{c}\text { Pseudomonas } \\
\text { aeruginosa }\end{array}$ & $\begin{array}{c}\text { Escherichia } \\
\text { coli }\end{array}$ & $\begin{array}{c}\text { Salmonella } \\
\text { typhi } \\
\text { Minimum }\end{array}$ & $\begin{array}{l}\text { Enterocooccus } \\
\text { faecalis } \\
\text { hibitory concen }\end{array}$ & $\begin{array}{c}\text { Streptococcus } \\
\text { pyrogenes } \\
\text { ions }(\mu \mathrm{g} / \mathrm{mL})\end{array}$ & $\begin{array}{c}\text { Staphylococcus. } \\
\text { Aureus }\end{array}$ & $\begin{array}{l}\text { Candida } \\
\text { albicans }\end{array}$ \\
\hline A1 & $>500$ & $>500$ & 62.5 & 500 & 62.5 & 125 & $>500$ \\
\hline A2 & $>500$ & $>500$ & $>500$ & $>500$ & $>500$ & $>500$ & $>500$ \\
\hline A3 & $>500$ & 62.5 & $>500$ & $>500$ & 250 & $>500$ & 500 \\
\hline A4 & $>500$ & 31.25 & $>500$ & $>500$ & 500 & 250 & $>500$ \\
\hline B1 & $>500$ & 500 & $>500$ & $>500$ & $>500$ & 250 & 125 \\
\hline B2 & $>500$ & $>500$ & $>500$ & $>500$ & $>500$ & $>500$ & $>500$ \\
\hline B3 & $>500$ & 250 & 500 & $>500$ & 250 & 250 & $>500$ \\
\hline B4 & $>500$ & 62.5 & 125 & $>500$ & $>500$ & 62.5 & 125 \\
\hline Ciprofloxacin & $\leq 0.5$ & $\leq 0.5$ & $\leq 0.5$ & 125 & 7.8 & $\leq 0.5$ & 1 \\
\hline Cefuroxime & $>500$ & 250 & 3.9 & 500 & 500 & 31.25 & $>500$ \\
\hline Amoxicillin & 250 & $>500$ & 125 & $>500$ & 500 & 125 & 15.6 \\
\hline Fluconazole & - & - & - & - & - & - & 500 \\
\hline
\end{tabular}

A1-B4 represent the codes assigned to the synthesised compounds as shown in Table 1.

points, and retardation factor $\left(R_{f}\right)$ values and spectral data from ultraviolet-visible and infrared spectroscopy.

Tables 3 and 2 represent results from antimicrobial and anthelminthic screening, respectively.

\section{Discussion}

The antimicrobial activity of these eight synthesised azo dyes was determined against seven microorganisms: three Grampositive bacteria (Staphylococcus aureus (ATCC 25923),
Streptococcus pyrogenes (clinical strain), and Enterococcus faecalis (ATCC 29212)), three Gram-negative bacteria (Salmonella typhi (clinical strain), Pseudomonas aeruginosa (ATCC 27853), Escherichia coli (ATCC 251922)), and a fungus (Candida albicans (ATCC 10231)) using the highthroughput spot culture growth inhibition assay (HTSPOTi).

All the eight compounds exhibited antimicrobial activities but to various degree on the six human pathogenic microorganisms. Considering the compound A2 for 
instance, the chloro group at the para position of the compound A2 was not essential for activity; the substitution of the chlorine group increases lipophilicity, which could have made the molecule get stacked in biological membrane and cause nonbonding interaction with protein groups at the binding site [15]. The esterification of the carboxylic functional in the A1 group to the compound A3 (ester) diminishes activity especially against Salmonella typhi and Enterococcus faecalis; however, the activity of the ester was greatly improved against Escherichia coli by at least eightfold. The compound A1 had the greatest activity against Salmonella typhi and Streptococcus pyogenes with an MIC of $62.5 \mu \mathrm{g} / \mathrm{mL}$ followed by good activity against Staphylococcus aureus. All the compounds tested showed no activity against E. faecalis with the exception of the compound A1, which had little activity with an MIC of $500 \mu \mathrm{g} / \mathrm{mL}$. The compound A4 (naphthol template maintained with $-\mathrm{SO}_{2} \mathrm{NH}_{2}$ : sulphonamide mimic) showed increase in activity against $E$. coli and Candida albicans by at least fifteen-fold and onefold, respectively. The presence of the $-\mathrm{SO}_{2} \mathrm{NH}_{2}$ group rather decreased drastically the activity of $\mathrm{A} 4$ against the other organisms. Considering the substituents on the compound $\mathrm{A} 1$ (carboxylic acid) and A3 (the ester group) (clogP: 5.24 (ChemBioDraw Ultra, Version 14)) are less polar than the carboxylic acid group, which allows it to penetrate lipid membranes. The ester group also makes the molecule behave as a prodrug of which is susceptible to microbial esterases to yield the active carboxylic acid group [16]. Notwithstanding this, the esterases released by the microbes could have degraded the ester hence decreasing the activity, or the ester remains inactive until it is acted upon by the microbial enzymes.

The compound A4 with the sulphonamide group exhibited an activity against Staphylococcus aureus with an MIC of $250 \mu \mathrm{g} / \mathrm{mL}$ in the assay. This means that the sulphonamide derivative is more active against Gram-negative E. coli. It has been noticed that antimicrobial activities of sulfonamides increases when bulky heterocycles are introduced on their structural templates. For instance, sulfasalazine and sulphamethoxazole are employed in treating various bacterial infections [17]. Overall, the compound A1 was the most active against the organisms, whilst A2 did not show any antimicrobial effect.

With the phenolic azo dye derivatives, the compound B4 showed moderate activity against Salmonella typhi with an MIC of $125 \mu \mathrm{g} / \mathrm{mL}$ and significant activity against $E$. coli and Staphylococcus aureus with MICs of $62.5 \mu \mathrm{g} / \mathrm{mL}$, respectively. Compounds B1 and B4 showed moderate activity against Candida albicans with an MIC of $125 \mu \mathrm{g} / \mathrm{mL}$. There was drastic reduction in the activity of the compound B3 indicating that the presence of chlorine at the ortho position affects activity. The compound B1 with the carboxylic acid group had reduced the activity throughout against the microorganisms. Esterification of carboxylic acid with the ethyl group diminished the antimicrobial activity completely. Comparing A1 and B1 built on carboxylic acid template, the naphtholic derivative (A1) was more active generally against the organisms compared to its corresponding phenolic derivative.
Overall, B4 showed good antimicrobial activity against most of the organisms with significant MICs. The compound A1 is a broad spectrum; A4 is potent mainly against Gramnegative bacteria with very little activity against Grampositive bacteria; B4 is also a broad spectrum with little antifungal activity and hence holds potential for future development into novel antimicrobial agents. It can be concluded that the naphtholic derivatives are more potent than the phenolic derivatives in terms of the antimicrobial activity. Nevertheless, none of the synthesised compounds showed good activity against $P$. aeruginosa, which is a wellknown notorious Gram-negative organism due to its efflux pumps, resistant genes, and thick biofilm inhibition. Pseudomonas aeruginosa is now to be responsible for $65-80 \%$ of microbial infections, and hence, more work need to be carried out in structurally modifying this library of compounds to overcome Pseudomonas-related diseases $[18,19]$.

For the anthelminthic activities, it was noticed that the time taken for paralysis and death to occur was increasing as the concentration of the azo compounds reduces. It is observed that compound B4 (phenol with the nitro group) had the best activity with low paralysis and death time. It can be observed that the phenolic derivatives of the azo compounds had the best activity. It could be said that the naphtholic derivatives have a bulky group as compared to the phenolic derivatives; this bulkiness could have prevented the compounds from reaching their target site, hence, undermining specificity. There is the presence of steric hindrance in the naphtholic derivatives due to the position of the hydroxyl group, which could have affected the binding of the molecule. Therefore, an extra benzene group was not necessary for paralysis of the worms but rather a simple phenolic moiety.

\section{Data Availability}

Data are available from the laboratory of Pharmaceutical Chemistry Department, Faculty of Pharmacy and Pharmaceutical Sciences, KNUST,, Kumasi upon request.

\section{Conflicts of Interest}

The authors declare that there are no conflicts of interest regarding the publication.

\section{Acknowledgments}

The authors acknowledge all staff (teaching and nonteaching) of Pharmaceutical Chemistry Department, Faculty of Pharmacy and Pharmaceutical Sciences, KNUST, for their support.

\section{References}

[1] B. Aslam, W. Wang, M. I. Arshad et al., "Antibiotic resistance: a rundown of a global crisis," Infection and Drug Resistance, vol. 11, pp. 1645-1658, 2018.

[2] J. T. Nisar and K. Subramaniam, "Enzymatic degradation of azo dyes-a review," International Journal of Environmetal Sciences, vol. 1, no. 6, pp. 1250-1260, 2011. 
[3] K.-T. Chung, "Azo dyes and human health: a review," Journal of Environmental Science and Health, Part C, vol. 34, no. 4, pp. 233-261, 2016.

[4] A. H Shridhar, J. Keshavar, S. K. Peethambar, and H. J. Hoskeri, "Synthesis and biological activities of Bis alkyl 1,3,4-oxadiazole incorporated azo dye derivatives," Arabian Journal of Chemistry, vol. 9, no. S2, pp. S1643-S1648, 2016.

[5] C. Kantar, H. Akal, B. Kaya, F. Islamoğlu, M. Türk, and S. Şaşmaz, "Novel phthalocyanines containing resorcinol azo dyes; synthesis, determination of $\mathrm{pKa}$ values, antioxidant, antibacterial and anticancer activity," Journal of Organometallic Chemistry, vol. 783, pp. 28-39, 2015.

[6] G. A. Pankey and L. D. Sabath, "Clinical relevance of bacteriostatic versus bactericidal mechanisms of action in the treatment of Gram-positive bacterial infections," Clinical Infectious Diseases, vol. 38, no. 6, pp. 864-870, 2004.

[7] J. Kovač, N. Gavarić, F. Možina, and S. Smole, "Antimicrobial and resistance modulatory activity of Alpinia katsumadai seed phenolic extract, essential oil and post-distillation extract," Food Technology and Biotechnology, vol. 52, no. 2, pp. 248254, 2014.

[8] S. Lo, C. Edlund, and C. E. Nord, "Metronidazole is still the drug of choice for treatment of anaerobic infections," Clinical Infectious Diseases, vol. 50, no. Supplementary 1, pp. S16-S23, 2010.

[9] A. K. Mitra and A. R. Mawson, "Neglected tropical diseases: epidemiology and global burden," Tropical Medicine and Infectious Disease, vol. 2, no. 3, 2017.

[10] S. O'Brien, "The neglected tropical diseases: a challenge we could rise to-will we?" All-Party Parliamentary Group on Malaria and Neglected Tropical Diseases (APPMG), WHO, pp. 1-15, Geneve, Switzerland, 2008.

[11] I. O. Okonko, E. A. Fajobi, T. A. Ogunnusi, A. A. Ogunjobi, and C. U. Obiogbolu, "Antimicrobial chemotherapy and sustainable development: the past, the current trend, and the future," African Journal Biomedical Research, vol. 11, no. 3, pp. 235-250, 2010.

[12] W. Kofie, C. D. Amengor, and R. K Adosraku, "Synthesis and evaluation of antimicrobial properties of azo dyes," International Journal of Pharmacy and Pharmaceutical Sciences, vol. 7, no. 4, pp. 5-8, 2015.

[13] C. A. Danquah, A. Maitra, S. Gibbons, J. Faull, and S. Bhakta, "HT-SPOTi: a rapid drug susceptibility test (DST) to evaluate antibiotic resistance profiles and novel chemicals for antiinfective drug discovery," Current Protocols in Microbiology, vol. 40, no. 1, pp. 1-17, 2016.

[14] K. R. Raghavendra and K. A. Kumar, "Synthesis and their antifungal, anthelmintic and dyeing properties of some novel azo dyes," International Journal of Pharmaceutical, Chemical and Biological Sciences, vol. 3, no. 2, pp. 275-280, 2013.

[15] M. Srejber, M. Melíková, J. Jurac, V. Bazgier, and K. Berka, "MolMeDB : molecules on membranes database," Database, vol. 2019, pp. 1-9, 2019.

[16] K. Sayali, P. Sadichha, and S. Surekh, "Review article microbial esterases: an overview," International Journal of Current Microbiology and Applied Sciences, vol. 2, no. 7, pp. 135-146, 2013.

[17] A. Saylam, Z. Seferoğlu, and N. Ertan, "Azo-8-hydroxyquinoline dyes: the synthesis, characterizations and determination of tautomeric properties of some new phenyl- and heteroarylazo-8-hydroxyquinolines," Journal of Molecular Liquids, vol. 195, pp. 267-276, 2014.

[18] P. N. Jimenez, P. NadalKoch, G. Thompson, J. A. Xavier, K. BCool, and R. H. Quax, "The multiple signaling systems regulating virulence in Pseudomonas aeruginosa," Microbiology and Molecular Biology Reviews, vol. 76, no. 1, pp. 46-65, 2012.

[19] S. B. Zaman, M. A. Hussain, R. Nye, V. Mehta, K. T. Mamun, and N. Hossain, "A review on antibiotic resistance: alarm bells are ringing," Cureus, vol. 9, no. 6, pp. 1-9, 2017. 